\title{
Modified Blalock-Taussig Shunt: A Single-Center Experience and Follow-Up
}

\author{
Dongxu Li, MD, Yabo Wang, MD, Ke Lin, MD, Qi An, MM \\ Department of Cardiovascular Surgery, West China Hospital, Sichuan University, Sichuan, P.R. China
}

\section{ABSTRACT}

Background: The modified Blalock-Taussig shunt (MBTS) is used to palliate patients with restrictive pulmonary blood flow in complex cardiac anomalies. We describe the immediate and follow-up results of patients with MBTS in our center.

Methods: Patients who received MBTS (excluding those with hypoplastic left heart syndrome) from May 2008 to December 2018 were retrospectively identified. Hospital records were evaluated to determine patient demographics, diagnoses, and perioperative data. Patients were followed up by echocardiograph to evaluate the patency of the graft until stage II procedure or death.

Results: MBTS was performed in 25 patients by 2 surgeons; $16 \%$ were neonates, and $60 \%$ had pulmonary atresia and $24 \%$ tetralogy of Fallot. The patients' median age was 2.6 months (range 0.2 to 372 ), and median weight was 5.3 $\mathrm{kg}$ (range 1.9 to 45$)$. Preoperative oxygen saturation $\left(\mathrm{SaO}_{2}\right)$ was $68.7 \% \pm 7.8 \%$. Forty-eight percent of patients received a $3.5-\mathrm{mm}$ graft, and $20 \%$ received a concomitant pulmonary arterioplasty with cardiopulmonary bypass. Postoperative $\mathrm{SaO}_{2}$ was $83.2 \% \pm 3.6 \%$, significantly different from preoperative $\mathrm{SaO}_{2}(P<.05)$. Follow-up duration was 1.2 years (range 0.3 to 7.8 ), with no graft blockage. Three patients died in hospital from cardiorespiratory decompensation after MBTS with concomitant pulmonary arterioplasty. The median age of patients receiving a stage II procedure was 1 year (range 0.4 to 17.4 ). Actuarial 1 -year survival was $79.7 \%$ (95\% confidence interval $53.1 \%$ to $92.2 \%$ ).

Conclusion: MBTS continues to be valuable for palliation of complicated cyanotic congenital heart disease, yet mortality was considerable with concomitant pulmonary arterioplasty. With effective coagulation, the patency rate of grafts was high.

\section{INTRODUCTION}

The Blalock-Taussig shunt was designed to improve arterial oxygen saturation $\left(\mathrm{SaO}_{2}\right)$ in "blue" babies by increasing pulmonary blood flow through the subclavian artery bypass to the pulmonary artery [Blalock 1945]. This landmark procedure was then modified and widely performed until the present [de Leval 1981; Bove 1987; McKay 1980; Sasikumar

Received August 16, 2019; accepted December 10, 2019.

Correspondence: Qi An, No. 37 Guo Xue Xiang, Chengdu, Sichuan, 610041, P.R. China; 86028 85422897; fax: 8602885421833 (e-mail: cardioanqi2013@163.com).
2017]. The modified Blalock-Taussig shunt (MBTS) was identified to secure stable pulmonary blood flow and growth of the pulmonary artery in cyanotic patients with restrictive pulmonary blood flow [Rao 2000; Elella 2014]. With growing experience, however, many centers have chosen to perform the primary corrective procedure [Di Donato 1991; Gustafson 1988]. Although comparisons between the multistage procedure and primary total repair have been unclear, some centers have chosen MBTS as stage I palliation after considering the risks of primary correction [Sasikumar 2017; Nakashima 2014; Alsoufi 2015]. Some of them have reported their own experiences with MBTS, yet results of the analyses, especially involving risk factors, were not consistent [Williams 2007; Petrucci 2011; McKenzie 2013].

Therefore, we retrospectively reviewed the patients who received MBTS in our center for the past 10 years and report the early and mid-term outcomes. We also analyze the significant risk factors for mortality.

\section{METHODS}

\section{Patients}

A retrospective chart review of patient undergoing MBTS in our center from May 2008 to December 2018 was done. This study was approved by the Medical Ethics Committee of West China Hospital, Sichuan University; need for individual patient consent was waived.

Patients were diagnosed by echocardiograph, with or without catheter intervention. All patients with single ventricle or biventricle receiving MBTS were included. Exclusion criteria were as follows: (1) diagnosis of hypoplastic left heart syndrome; or (2) MBTS not the initial cardiac procedure. Full sternotomy was the only approach. Cardiopulmonary bypass (CPB) was on standby if appropriate. Shunt palliation was performed from brachiocephalic trunk to the right pulmonary artery with Gore-Tex polytetrafluoroethylene graft (W.L. Gore and Associates, Phoenix, AZ). Patent ductus arteriosus (PDA) ligation or pulmonary arterioplasty was performed if appropriate. Patients were transferred to the intensive care unit (ICU) after surgery. Heparin infusion was started with 5 to $10 \mathrm{IU} / \mathrm{kg} / \mathrm{h}$, followed by therapeutic dose 2 hours postoperatively or as drainage decreased. Patients were given aspirin $30 \mathrm{mg} / \mathrm{kg} / \mathrm{d}$ after extubation. Oral antiplatelet administration lasted until the stage II procedure.

\section{Outcomes and Variables}

The following variables were collected at baseline and after surgery: perioperative data including procedure type, 
Table 1. Patient Characteristics*

\begin{tabular}{lc}
\hline Characteristic & Value \\
\hline Patients & 25 \\
Age $(\mathrm{mo})$ & $2.6(0.2-372)$ \\
$\mathrm{Weight}(\mathrm{kg})$ & $5.3(1.9-45)$ \\
$\mathrm{Gender}(\mathrm{M} / \mathrm{F})$ & $14 / 11$ \\
$\mathrm{SaO}_{2}$ before shunt $(\%)$ & $68.7 \pm 7.8$ \\
$\mathrm{Cardiac}$ diagnosis & \\
Pulmonary atresia & \\
$\quad$ Ventricular septal defect & $12(48)$ \\
$\quad$ Intact ventricular septum & $3(12)$ \\
Pulmonary stenosis & \\
$\quad$ Double outlet right ventricle $\backslash$ tetralogy of Fallot & $6(24)$ \\
$\quad$ Right ventricular dysplasia & $1(4)$ \\
Corrected transportation of great arteries & $1(4)$ \\
Tricuspid atresia & $2(8)$ \\
\hline
\end{tabular}

*Data are $n$, median (range), mean $\pm S D$, or $n(\%)$.

$\mathrm{CPB}$ usage, and shunt size; $\mathrm{SaO}_{2}$; duration of inotrope infusion; ventilation time; duration of ICU and hospital stay; and incidence of bleeding, reoperation, and complications, including mortality.

\section{Follow-Up}

Patients were followed up for 3 months after the initial procedure. At each visit, besides vital examination, an echocardiograph was performed for the pulmonary artery anatomy, shunt patency, ventricular function, and timing and planning of a stage II procedure.

\section{Statistical Analysis}

Clinical characteristics are presented as mean with standard deviation (SD), median with range, or frequency and percentage as appropriate. Categorical variables were compared using Fisher's exact test. Continuous variables were compared between groups using Student's t test or Mann-Whitney test as appropriate. Univariate analysis was performed to identify the risk factors for hospital mortality. Because of the small sample size, multivariate logistic regression was not performed. The Kaplan-Meier method was used to estimate the probability of survival. $P$ values $<.05$ were considered significant. Analyses were carried out with Stata software (version 14.0, Stata Corp., College Station, TX).

\section{RESULTS}

Twenty-three patients were included during the study period; 4 (16\%) were neonates; 16 (64\%) were infants; $3(12 \%)$ were children; and $2(8 \%)$ were adults. The characteristics of
Table 2. Perioperative Data*

\begin{tabular}{lc}
\hline Item & Value \\
\hline Modified Blalock-Taussig shunt & 25 \\
With pulmonary arterioplasty (CPB use) & $5(20)$ \\
With PDA ligation & $12(48)$ \\
Shunt size (mm) & $4(3.5-6)$ \\
3.5 & $12(48)$ \\
4 & $6(24)$ \\
5 & $1(4)$ \\
6 & $6(24)$ \\
SaO after shunt (\%) & $83.2 \pm 3.6$ \\
Ventilation time (d) & $7.0 \pm 3.3$ \\
Infusion of inotropes (d) & \\
Epinephrine & $7.2 \pm 3.1$ \\
Norepinephrine & $7.1 \pm 2.1$ \\
Milrinone & $10.6 \pm 2.9$ \\
Pituitrin & $5.0 \pm 1.0$ \\
ICU stay (d) & $13.7 \pm 6.0$ \\
Hospital stay (d) & $27.8 \pm 9.9$ \\
Death & $3(12)$ \\
\hline
\end{tabular}

*Data are $\mathrm{n}, \mathrm{n}(\%)$, mean $\pm \mathrm{SD}$, or median (range).

patients are shown in Table 1. The median age of patients was 2.6 months (range 0.2 to 372), and weight was $5.3 \mathrm{~kg}$ (range 1.9 to 45 ). Preoperative $\mathrm{SaO}_{2}$ was $68.7 \% \pm 7.8 \%$. Underlying cardiac anomalies included pulmonary atresia with ventricular septal defects $(\mathrm{n}=12,48 \%)$, pulmonary atresia with intact ventricular septum $(n=3,12 \%)$, tetralogy of Fallot $(n=6$, $24 \%)$, pulmonary stenosis with right ventricular dysplasia $(\mathrm{n}=$ $1,4 \%)$, corrected transportation of great arteries $(\mathrm{n}=1,4 \%)$, and tricuspid atresia $(\mathrm{n}=2,8 \%)$.

Perioperative data are shown in Table 2. Five patients $(20 \%)$ with pulmonary atresia underwent MBTS with pulmonary arterioplasty. Twelve patients (48\%) received concomitant PDA ligation. Twelve patients $(48 \%)$ received a $3.5-\mathrm{mm}$ graft, with median weight of $4.2 \mathrm{~kg}$ (range 1.9 to 6). Postoperative $\mathrm{SaO}_{2}$ was $83.2 \% \pm 3.6 \%$, significantly improved compared with preoperative $\mathrm{SaO}_{2}(P<.05)$. The ventilation time in ICU was 7.0 \pm 3.3 days. Infusion of vasoactive agents included epinephrine $(\mathrm{n}=17,68 \%)$, norepinephrine $(\mathrm{n}=10,40 \%)$, milrinone $(\mathrm{n}=7$, $28 \%)$, and pituitrin ( $\mathrm{n}=3,12 \%)$. The mean duration of ICU stays was $13.7 \pm 6.0$ days, and in hospital, $27.8 \pm 9.9$ days. Three patients died in the ICU from cardiorespiratory decompensation (Table 3). All were diagnosed with pulmonary atresia with ventricular septal defects and received MBTS with pulmonary arterioplasty under CPB. Results of univariate analysis for risk factors of hospital mortality are shown in Table 4. There was a significant difference only in pulmonary arterioplasty/CPB use between those who survived and those who died $(P<.05)$. 
Table 3. Hospital Mortality Details*

\begin{tabular}{lccccc}
\hline Diagnosis & $\begin{array}{c}\text { Age } \\
(\mathrm{mo})\end{array}$ & $\begin{array}{c}\text { Weight } \\
(\mathrm{kg})\end{array}$ & $\begin{array}{c}\text { Shunt Size } \\
(\mathrm{mm})\end{array}$ & Surgery & $\begin{array}{c}\text { Date of Death } \\
\text { (postoperative day) }\end{array}$ \\
\hline PA/VSD: PDA & 2.5 & 5 & 4 & MBTS with pulmonary arterioplasty and & Cardiorespiratory decompensation \\
PA/VSD: ASD & 6.9 & 6.5 & 4 & MBTS with pulmonary arterioplasty & Cardiorespiratory decompensation \\
PA/VSD: PDA & 12 & 7.5 & 6 & MBTS with pulmonary arterioplasty and & Cardiorespiratory decompensation \\
\hline
\end{tabular}

*ASD, atrial septal defect; PA, pulmonary atresia; VSD, ventricular septal defect.

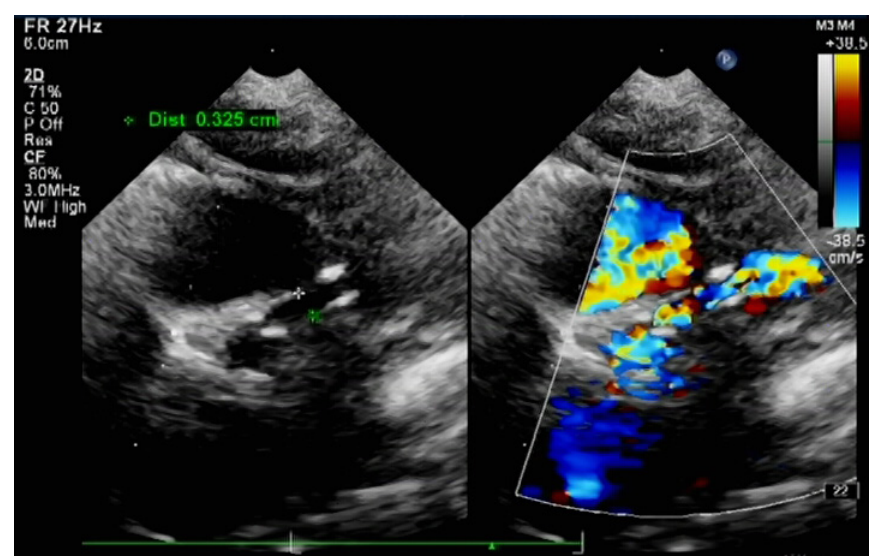

Figure 1. Echocardiograph at follow-up to evaluate the patency of the graft.

Follow-up data are shown in Table 5. Follow-up duration was 1.2 years (range 0.3 to 7.8 ). According to the echocardiographs, there was no graft blockage before the stage II procedure (Figure 1). Twelve patients received a stage II procedure, at the mean age of 1 year (range 0.4 to 17.4 ). One patient with a diagnosis of pulmonary atresia with ventricular septal defects died 1 year after the initial MBTS. A Kaplan-Meier plot is shown in Figure 2. Actuarial 1-year survival was 79.7\% (95\% confidence interval $53.1 \%$ to $92.2 \%$ ).

\section{DISCUSSION}

MBTS was designed initially to palliate poor $\mathrm{SaO}_{2}$ in patients with restrictive pulmonary blood flow such as tetralogy of Fallot [Blalock 1945; de Leval 1981; Bove 1987]. Our results show significant improvement in $\mathrm{SaO}_{2}$ in patients after shunt placement. This palliation is still used and has been introduced in patients with hypoplastic left heart syndrome (HLHS) [Williams 2007; Norwood 1981]. Because of the difference between restrictive pulmonary blood flow disease and HLHS in anatomic features and surgical strategies, in this study we excluded patients with HLHS and focused on those with restrictive pulmonary blood flow. Many studies have similarly excluded patients with HLHS [Sasikumar

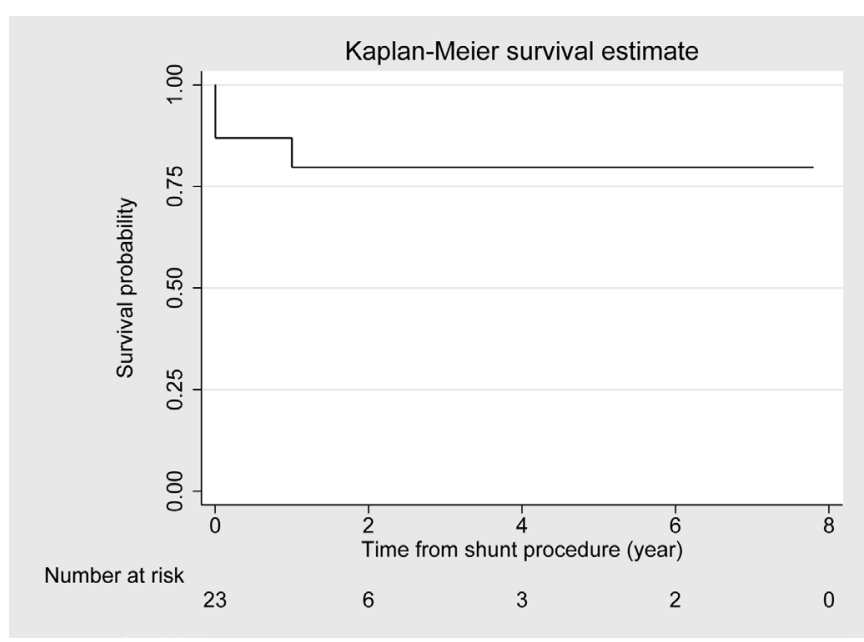

Figure 2. Kaplan-Meier survival plot after the initial palliation.

2017; Williams 2007; Dirks 2013]. Sasikumar et al [2017] and Petrucci et al [2011] excluded patients with nonconfluent pulmonary artery or concurrent pulmonary arterioplasty; however, we believe that MBTS can improve pulmonary blood flow and that it is sometimes necessary to perform concomitant pulmonary arterioplasty. Thus, we included all patients with or without pulmonary arterioplasty.

The age at MBTS was not limited to $<1$ month old, yet some studies only reported this palliation in neonates [Rao 2000; Alkhulaifi 2000]. Studies by Sasikumar et al [2017] and McKenzie et al [2013] included neonates and children. Singh et al [2014] divided their patients into neonates, infants, and older children and compared operative outcomes between them. We reviewed our patients during the past 10 years and also included neonates, infants, children, and even adults. For an adult with single ventricle and pulmonary stenosis, MBTS might be the bridge to transplantation or just optimal palliation [Angeli 2012]. One adult patient was missed during follow-up; the other was still under follow-up.

It is controversial whether to perform MBTS via sternotomy or thoracotomy [Kandakure 2010]. Odim et al [1995] reported easier manipulation when performing MBTS via sternotomy than thoracotomy. Considering the distortion of the distal pulmonary artery in thoracotomy and the lesser 
Table 4. Univariate Analysis of Risk Factors for Hospital Mortality*

\begin{tabular}{lccc}
\hline Variable & Alive $(\mathrm{n}=22)$ & Dead $(\mathrm{n}=3)$ & $P$ \\
\hline Age $(\mathrm{mo})$ & $2.6(0.2-372)$ & $2.5(1-6.9)$ & $.558 \dagger$ \\
Weight $(\mathrm{kg})$ & $5.3(1.9-45)$ & $6.5(5-7.5)$ & $.707 \dagger$ \\
$\mathrm{SaO}_{2}(\%)$ & $68.6 \pm 7.8$ & $69.3 \pm 9.1$ & $.888 \ddagger$ \\
Shunt size $(\mathrm{mm})$ & $4.2 \pm 1.0$ & $4.7 \pm 1.2$ & $.505 \ddagger$ \\
Pulmonary arterioplasty & 2 & 3 & $.004 \S$ \\
Pulmonary atresia & 12 & 3 & $.250 \S$ \\
\hline
\end{tabular}

*Data are median (range), mean $\pm \mathrm{SD}$, or $\mathrm{n}$.

†Mann-Whitney test.

$\ddagger$ Student's $t$ test.

$\S$ Fisher's exact test.

bleeding risk in re-sternotomy, sternotomy was the only approach used in our center. Based on the pre- and intraoperative evaluation of the size of the pulmonary artery trunk, we might do a pulmonary arterioplasty with a pericardial patch if possible. We decided the graft size depended on body weight, with consideration of making it not too small to lead to shunt thrombosis or too big to result in pulmonary overflow [Şişli 2019]. Basically, a 3-mm graft was used for children $3 \mathrm{~kg}$ or lower in body weight, whereas a $3.5-\mathrm{mm}$ graft was used for children $\sim 3.5 \mathrm{~kg}$ [Dirks 2013]. Unfortunately, there was just a $3.5-\mathrm{mm}$ graft for the patient who weighed $1.9 \mathrm{~kg}$, but this patient was alive at the last follow-up.

Three patients died from cardiorespiratory decompensation 1 day after surgery. According to our analysis, pulmonary arterioplasty and $\mathrm{CPB}$ use might be risk factors for hospital mortality, but in other centers, the risk factor was explicitly CPB use. Alsoufi et al [2016] demonstrated that CPB use was a significant risk factor for mortality, and Petrucci et al [2011] and Dirks et al [2013] showed that there was no significant difference. Both studies were in neonates. Low weight, especially $<2.5 \mathrm{~kg}$, was a confirmed risk factor [Petrucci 2011; Dirks 2013; Singh 2014; Alsoufi 2016]. Other factors involving age, single ventricle, and shunt size were unclear [Petrucci 2011; McKenzie 2013; Dirks 2013; Singh 2014; Bove 2015]. Our study showed that age, weight, preoperative $\mathrm{SaO}_{2}$, shunt size, and pulmonary atresia were not significant risk factors. Even so, we also believe that the small sample size of our study might obscure results.

Time intervals to stage II surgery range from 3 months to 2 years according to different centers [Sasikumar 2017; Alsoufi 2016; Bove 2015; Ahmad 2008]. In our center, 12 patients $(54.5 \%)$ underwent planned surgery a median of 0.75 year (range 0.4 to 4.3 ) after shunt placement. Thanks to persistent standardized anticoagulation, no patients were found to have shunt blockage by thrombosis in or out of the hospital. Cases with shunt thrombosis have been found early after surgery [Dirks 2013; Singh 2014]. Dirks et al [2013] showed no association between smaller shunt size and occurrence of
Table 5. Follow-Up Data*

\begin{tabular}{lc}
\hline Item & Value \\
\hline Patients $(\mathrm{n})$ & 22 \\
Follow-up duration $(\mathrm{y})$ & $1.2(0.3-7.8)$ \\
Graft blockage & 0 \\
Stage Il procedure & \\
$\mathrm{n}$ & $12(54.5)$ \\
Age $(\mathrm{y})$ & $1(0.4-17.4)$ \\
Death & 1 \\
\hline
\end{tabular}

*Data are $\mathrm{n}$, median (range), or $\mathrm{n}(\%)$.

thrombosis. Singh et al [2014] thought that regular coagulation could protect patients from shunt thrombosis. In our study, 1 patient died for noncardiac reasons during follow-up. Thus, the total mortality in our center was $16 \%$, higher than the $7 \%$ to $10 \%$ of other centers [Williams 2007; Petrucci 2011; McKenzie 2013; Dirks 2013]. We believe the learning curve may explain the higher mortality in our center.

\section{LIMITATIONS}

There are several limitations to this study, including the inherent limitation with the retrospective single-arm design. Because of the small sample size, we could not use strict exclusion and stratify patients by age, weight, and diagnosis in the analysis of risk factors for mortality, nor could we perform multivariate regression analysis.

\section{CONCLUSION}

With improvement of $\mathrm{SaO}_{2}$, many patients underwent corrective procedures after the initial shunt. MBTS continues to be valuable for palliation of complicated cyanotic congenital heart disease, yet mortality was considerable with concomitant pulmonary arterioplasty. With effective coagulation, the patency rate of grafts was high.

\section{REFERENCES}

Ahmad U, Fatimi SH, Naqvi I, et al. 2008. Modified Blalock-Taussig shunt: Immediate and short-term follow-up results in neonates. Heart Lung Circ 17:54-58.

Alkhulaifi AM, Lacour-Gayet F, Serraf A, Belli E, Planché C. 2000. Systemic pulmonary shunts in neonates: Early clinical outcome and choice of surgical approach. Ann Thorac Surg 69:1499-1504.

Alsoufi B, Gillespie S, Mori M, Clabby M, Kanter K, Kogon B. 2016. Factors affecting death and progression towards next stage following modified Blalock-Taussig shunt in neonates. Eur J Cardiothorac Surg 50:169-177. 
Alsoufi B, Mori M, McCracken C, et al. 2015. Results of primary repair versus shunt palliation in ductal dependent infants with pulmonary atresia and ventricular septal defect. Ann Thorac Surg 100:639-646.

Angeli E, Pace Napoleone C, Balducci A, et al. 2012. Natural and modified history of single-ventricle physiology in adult patients. Eur J Cardiothorac Surg 42:996-1002.

Blalock A, Taussig HB. 1945. The surgical treatment of malformations of the heart in which there is pulmonary stenosis or pulmonary atresia. JAMA 128:189-202.

Bove EL, Kohman L, Sereika S, et al. 1987. The modified BlalockTaussig shunt: Analysis of adequacy and duration of palliation. Circulation 76(3 pt 2):III19-III23.

Bove T, Vandekerckhove K, Panzer J, De Groote K, De Wolf D, François K. 2015. Disease-specific outcome analysis of palliation with the modified Blalock-Taussig shunt. World J Pediatr Congenit Heart Surg 6:67-74.

de Leval MR, McKay R, Jones M, Stark J, Macartney FJ. 1981. Modified Blalock-Taussig shunt. Use of subclavian artery orifice as flow regulator in prosthetic systemic-pulmonary artery shunts. J Thorac Cardiovasc Surg 81:112-119.

Di Donato RM, Jonas RA, Lang P, Rome JJ, Mayer JE Jr., Castaneda AR. 1991. Neonatal repair of tetralogy of Fallot with and without pulmonary atresia. J Thorac Cardiovasc Surg 101:126-137.

Dirks V, Prêtre R, Knirsch W, et al. 2013. Modified Blalock Taussig shunt: A not-so-simple palliative procedure. Eur J Cardiothorac Surg 44:1096-1102.

Elella RA, Umereta N, Alabari I, Al Ahmadi M, Al Wadai A. 2014. The short- and long-term effect of Blalock-Taussig shunt size on the outcome after first palliative surgery for cyanotic heart diseases. Ann Saudi Med $34: 494-498$

Gustafson RA, Murray GF, Warden HE, Hill RC, Rozar GE Jr. 1988. Early primary repair of tetralogy of Fallot. Ann Thorac Surg 45:235-241.

Kandakure PR, Dharmapuram AK, Ramadoss N, Babu V, Rao IM, Murthy KS. 2010. Sternotomy approach for modified Blalock-Taussig shunt: Is it a safe option? Asian Cardiovasc Thorac Ann 18:368-372.
McKay R, de Leval MR, Rees P, Taylor JF, Macartney FJ, Stark J. 1980. Postoperative angiographic assessment of modified Blalock-Taussig shunts using expanded polytetrafluoroethylene (Gore-Tex). Ann Thorac Surg 30:137-145.

McKenzie ED, Khan MS, Samayoa AX, et al. 2013. The Blalock-Taussig shunt revisited: A contemporary experience. J Am Coll Surg 216:699704; discussion 704-706.

Nakashima K, Itatani K, Oka N, et al. 2014. Pulmonary annulus growth after the modified Blalock-Taussig shunt in tetralogy of Fallot. Ann Thorac Surg 98:934-940.

Norwood WI, Lang P, Casteneda AR, Campbell DN. 1981. Experience with operations for hypoplastic left heart syndrome. J Thorac Cardiovasc Surg 82:511-519.

Odim J, Portzky M, Zurakowski D, et al. 1995. Sternotomy approach for the modified Blalock-Taussig shunt. Circulation 92:II256-II261.

Petrucci O, O'Brien SM, Jacobs ML, Jacobs JP, Manning PB, Eghtesady P. 2011. Risk factors for mortality and morbidity after the neonatal Blalock-Taussig shunt procedure. Ann Thorac Surg 92:642-651; discussion 651-652.

Rao MS, Bhan A, Talwar S, Sharma R. 2000. Modified Blalock-Taussig shunt in neonates: Determinants of immediate outcome. Asian Cardiovasc Thorac Ann 8:339-343.

Sasikumar N, Hermuzi A, Fan CS, et al. 2017. Outcomes of BlalockTaussig shunts in current era: A single center experience. Congenit Heart Dis 12:808-814.

Singh SP, Chauhan S, Choudhury M, et al. 2014. Modified Blalock Taussig shunt: Comparison between neonates, infants and older children. Ann Card Anaesth 17:191-197.

Şişli E, Tuncer ON, Şenkaya S, et al. 2019. Blalock-Taussig shunt size: Should it be based on body weight or target branch pulmonary artery size? Pediatr Cardiol 40:38-44.

Williams JA, Bansal AK, Kim BJ, et al. 2007. Two thousand BlalockTaussig shunts: A six-decade experience. Ann Thorac Surg 84:20702075; discussion 2070-2075. 